\title{
Chroniques de géo' virale de Michel Lussault. A epidemia da Covid-19 e o olhar do geógrafo Michel Lussault
}

\author{
$1^{\text {a }}$ temporada: 10 episódios \\ $2^{\mathrm{a}}$ temporada: 4 episódios \\ YouTube da Ecole Urbaine de Lyon EUL, \\ recuperado de: https://www.youtube.com/c/EcoleUrbainedeLyonEUL/featured
}

\section{Jaime Oliva \\ Instituto de Estudos Brasileiros, Universidade de São Paulo.}

A epidemia provocada pelo vírus SARS-coV-2 foi declarada como uma pandemia no dia 11 de março de 2020 pela Organização Mundial de Saúde (OMS). Desde então, além da proliferação planetária do vírus, houve outra epidemia paralela: a epidemia de informações que acompanha o percurso da pandemia e a difunde, avassaladoramente, sem que consigamos formar ideias minimamente seguras sobre as representações sociais que são produzidas. 0 que se percebe são os rumores, as teorias conspiratórias e os conflitos gerados como efeitos dessa epidemia descontrolada das informações.

A impressionante cobertura dos meios de comunicação e as inúmeras plataformas digitais de universidades de várias partes do mundo (e/ou entidades científicas) desaguaram (e desaguam) diariamente, há mais de um ano, um volume extraordinário de dados numéricos, de gráficos -com infindáveis oscilações de curvas de incidência da doença e dos óbitos- e mapas e mais mapas de todos os países que têm como objetivo representar e rastrear a atividade, que é geográfica, do SARS-coV-2. Soma-se a esse primeiro fluxo informacional a enorme movimentação das editorias das revistas científicas/ acadêmicas e do mercado editorial comercial que trouxeram para o público especializado e para o público comum uma grande quantidade de textos científicos, que seriam aqueles que deveriam refletir uma maior maturação das ideias. Mas, parece que não é assim, tal o volume de publicações.

Algumas estratégias indevidas de publicação foram utilizadas para se chegar a tanto, como a reciclagem de textos já existentes antes da epidemia discutindo questões sanitárias, ou de ordem mais geral, e que foram rapidamente adaptados para a conjuntura da pandemia. Também textos produzidos sob demanda, por vezes com financiamento, e com prazos tirânicos para interpretar a pandemia no fogo dos acontecimentos. Pode-se dizer que o cabedal de textos científicos não foi produto apenas de ações autorais, mas foi um movimento editorial. Nada disso tem impedido muitos erros nas ações dos governos dos países mais afetados pela epidemia e falhas grosseiras nas previsões sobre o seu desdobramento. E, principalmente, não evita que partes importantes das populações de países como os EE.UU. e o Brasil sequer admitam que haja essa pandemia e que, na verdade, estamos diante de uma "conspiração de esquerda" chamada o "covidismo". ${ }^{1}$ Esse quadro fez com que o geógrafo Michel Lussault afirmasse que a pandemia, além de uma crise sanitária, é também uma crise política que se funda sobre uma crise informacional e semiológica.

Em que contexto Michel Lussault fez tal afirmação? Reforçado pelo confinamento social, o espaço digital foi mais inflacionado do que nunca, com uma gama impressionante de vídeos, vídeos-conferências e lives de fontes dos mais diversos mundos culturais, e na maior parte dessa "programação" a estrela máxima era SARS-coV-2. 0 mundo das universidades também se introduziu nesse espaço (sem o mesmo sucesso de público, é bom que se

1 Como diversas vezes afirmou o ex-Ministro das Relações Exteriores do Brasil, Ernesto Araújo. Ele foi ministro de janeiro de 2019 a março de 2021. 
Chroniques de géo' virale de Michel Lussault. A epidemia da Covid-19 e o olhar do geógrafo Michel Lussault JAIME OLIVA

diga), e no canal do YouTube da Ecole Urbaine de Lyon (EUL) podemos encontrar a afirmação mencionada de Michel Lussault. Lá ele criou uma série de dez vídeos denominada Chronique Géo-Virale. Esses episódios cobriram um período de 21 de março a 16 de abril de 2020. Depois disso, na França e na Europa Ocidental, a pandemia declinou, para retornar com força já no final do ano de 2020 e provavelmente isso deve ter estimulado Lussault a fazer uma segunda temporada de suas crônicas (um ano depois), agora reeditadas como Chroniques de géo' virale. A essa altura ele já havia lançado um pequeno livro que tinha como base as primeiras dez crônicas, também denominado Chroniques de géo' virale, editado pela École Urbaine de Lyon.

Depois de acompanhar todos os episódios, a sensação que fica é que encontramos no oceano caótico de informações e reflexões duvidosas sobre a pandemia da Covid-19, algumas reflexões de grande valor elucidativo e, também, provocativo. Isso não é casual, não há improviso conjuntural. Há sim uma conexão consistente dessas reflexões com a obra publicada nos últimos vinte anos por esse geógrafo, cujo marco epistemológico é o lançamento em 2003 do indispensável Dictionnaire de la géographie et de l'espace des sociétés, dirigido por ele e pelo também geógrafo Jacques Lévy.

De fato, as ideias sedimentadas por ele e seu parceiro nessa obra ${ }^{2}$ fecundaram uma série de quatro livros de Lussault. $^{3} 0$ primeiro deles é o notável L'Homme spatial. La construction sociale de l'espace humain. Nesse, o autor se empenha numa teorização demonstrada sobre a pertinência de se investir num ponto cego ainda presente no âmbito das ciências sociais: o ponto de vista do espaço. Ele irá argumentar sobre o valor heurístico da exploração desse ponto ao longo da obra e, no Capítulo 3 -um dos mais interessantes-, vai tratar das operações espaciais, um elemento chave da teoria

2 Como qualquer dicionário, se trata de uma obra coletiva, porém o programa teórico para se pensar os espaços das sociedades e a geografia contemporânea que conduz o dicionário, tem em Lussault e Lévy seus dois grandes artífices.

3 L'Homme spatial. La construction sociale de l'espace humain (2007); De la lutte des classes à la lutte des places (2009); L'Avènement du Monde. Essai sur l'habitation humaine de la Terre (2014); Hyper-lieux. Les nouvelles géographies de la mondialisation (2017). que ele está organizando: operadores participam da dinâmica espacial e interferem nas espacialidades praticadas no meio social. Ele estrutura um quadro identificando esses operadores: os atores individuais e coletivos humanos propriamente; os híbridos (paisagem, objetos espaciais); os nãohumanos -animais, vírus, etc.- e os artefatos e objetos tecnológicos (Lussault, 2007:149). Sobre essa diversidade de operadores ele diz: "deve-se levar a sério a ação do menor operador e abordar sistematicamente esse domínio de atividade, enquanto atividade que organiza a espacialidade humana" (Lussault, 2007:148).

No esforço de teorizar demonstrando a pertinência da elaboração, ele usará um exemplo bem interessante destacado sob o título de $L^{\prime}$ intervention sociale d'un actant spatial: le coronavirus du Sras. ${ }^{4}$ Trata-se de uma epidemia provocada por um coronavírus em 2002, cujo primeiro caso aparece na China, mas que não adquiriu caráter pandêmico, e em 2003 pela avaliação da OMS já não tinha mais cadeias de transmissão ativas. A avaliação feita sobre essa epidemia (lembrando que para efeitos de demonstração teórica) e a integração desse vírus nas práticas espaciais naquelas circunstâncias é rica sob vários aspectos e muito do que ele já elaborava na ocasião será retomado nas Chroniques de géo' virale. Lussault não reflete na questão sanitária e na força operativa do vírus como um especialista em geografia da saúde. Não vem daí seu interesse, embora não seja um tema externo à sua postura teórica. Os vírus (e demais operadores) já se encontravam incubados no coração de sua teoria. Daí que não é improviso e nem foi um apelo acadêmico/midiático que o levou para os vídeos sobre a epidemia da Covid-19. Vamos a eles.

Destacaremos alguns pontos que conduzem as crônicas. Um primeiro ponto, que é chave, é o argumento de que a pandemia da Covid-19 nos mostra que não vivemos apenas entre nós e que o restante do planeta, o meio biofísico, é uma fonte externa à nossa disposição. Em harmonia com suas elaborações anteriores, Lussault insiste que nossos mundos sociais se compõem com todos esses

4 A intervenção social de um actante (operador) espacial: o coronavírus da SRAS (síndrome respiratória aguda severa). 
Chroniques de géo' virale de Michel Lussault. A epidemia da Covid-19 e o olhar do geógrafo Michel Lussault JAIME OLIVA

elementos não-humanos e que vivemos com eles, pois eles são internos aos nossos mundos sociais operando nas dinâmicas sociais e espaciais.

Um segundo ponto explora o destino do vírus. Ora, se na sua origem a dinâmica do vírus é biológica e a lógica da infecção é sempre a mesma, a lógica do contágio é totalmente diversificada, pois ela representa a integração da dimensão biológica com as características intrinsicamente diferenciadas dos espaços de nossas vidas, que para o vírus são os espaços epidêmicos. Esses espaços são anisotrópicos e as diferenciações encontram-se em todas as escalas e, certamente, afetam os índices de contaminação e os de mortalidade da Covid-19. Ainda não se sabe tudo sobre a lógica de infecção desse vírus, mas sabemos muito menos sobre as lógicas de contágio, visto a complexidade multifatorial que irá operar na epidemia nos diferentes espaços de nossas vidas.

Para entender o contágio deve-se inicialmente perceber que o vírus é ele próprio um operador espacial. Por quê? Um dado elementar é que para existir o vírus transfere-se espacialmente de um corpo (humano, no caso) para outro. Essa escala espacial do vírus se somará com a escala espacial da vida do ser contaminado e nessa progressão pode-se chegar à escala planetária afetando as dinâmicas espaciais/sociais mais amplas de nossas vidas. Logo, ele é mesmo um operador dotado de grande força espacial, inclusive geopolítica.

Um terceiro ponto a se destacar é que na tentativa de apreender as lógicas de contágio do SARS-coV-2, deve-se considerar inicialmente as características dos espaços humanos atuais, cuja geografia possui algumas marcas fortes que combinadas dão um caráter global ao vírus. As grandes concentrações urbanas cada vez mais integradas e o fenômeno da circulação de tudo e de todos transformam o vírus num viajante planetário capaz de uma incrível performance de subsistência. Isso atrelado ao fato biológico de que a letalidade da infecção não é grande e ao não tirar a vida da maioria dos hospedeiros ele próprio se mantem na sua saga espacial e acelerada de transferência para outros corpos. Lussault destaca essa especificidade, em comparação com outras doenças contagiosas mais letais que terminam tendo um potencial menor de expansão geográfica, como tuberculoses, malárias, etc. Assim, potencialmente, a epidemia da Covid-19 tem condições de ser mais exaustiva em termos geográficos e de ser, de fato, uma pandemia. Esse é, portanto, o ponto que explicita a globalização do vírus. Porém, esse não é o ponto de chegada para compreendermos as lógicas de contágio para aprendermos a viver com esse vírus (o que implica também tentar eliminá-lo). É apenas o ponto de partida.

Um outro ponto tratado nas crônicas (o nosso quarto destaque) é muito caro aos geógrafos, mas deveria ser caro a todas as especialidades e ao público em geral. A globalização que integra os espaços de nossas vidas, com todas as desigualdades que conhecemos, transforma o vírus SARS-coV-2 numa realidade planetária, mas ela não é um processo que interrompe a diferenciação desses espaços. Assim, segundo a hipótese de Lussault, as diversas dinâmicas de contágio que estamos observando no planeta, há mais de um ano, para serem compreendidas terão que ser estudadas segundo a admissão inicial que a cada caso estamos diante de um quadro sempre informado por múltiplos fatores em combinações específicas, o que não facilita em nada o trabalho, mas é essa condição complexa do contágio.

Para ele um passo importante é identificar alguns desses fatores (eles em si, também complexos). São cinco os fatores que, inicialmente, devem ser levados em consideração: 1) 0 modo como o vírus entrou num dado espaço de contágio (turismo, internacional e nacional, por exemplo) e como ele se espalhou via os super difusores, que são os lugares de aglomerações de público bastante ativo e com tempo de exposição (templos religiosos, estádios esportivos, festas, etc.); 2) As características sociodemográficas de uma população: constituição etária, prevalência de comorbidades e obesidade, as condições sociais em que vivem os idosos, desigualdades sociais e raciais; ${ }^{5} 3$ ) As condições do sistema de saúde e toda a rede

5 Ficou atestado que nos EE.UU. os afro-americanos foram as maiores vítimas. 
Chroniques de géo' virale de Michel Lussault. A epidemia da Covid-19 e o olhar do geógrafo Michel Lussault JAIME OLIVA

de cuidados que uma região pode oferecer; 4) As políticas de Estado de prevenção e combate à epidemia. Foram eficientes ou fracassaram? Mas não só isso: como a própria sociedade civil se preparou e admitiu alterar comportamentos diante da epidemia? 5) A configuração geográfica de cada país/região e seu funcionamento, o que sabemos ser fundamental na lógica do contágio, mas muito difícil de mensurar diante do enorme número de variáveis que operam e da diversidade de espacialidades que são praticadas.

Esses cinco fatores podem formar um sistema explicativo complexo, mas deve-se verificar como cada fator intervém e como cada um é alterado pelos outros em cada situação. O que se pode afirmar de início é que muito difícil a manifestação de padrões comuns de contágio. Se tivermos em conta um país das dimensões e da diversidade regional como o Brasil, pode-se rapidamente perceber que ele foi (e está) assolado por dinâmicas epidêmicas diferenciadas. Lussault lembra uma situação contraintuitiva na região italiana da Lombardia, pois ali havia um sistema médico consistente e áreas urbanas mais atingidas não tinham a densidade demográfica do maior centro urbano da região que é Milão. Outra situação semelhante foi em Nova York, cuja área mais densa (Manhattan) também não foi a mais afetada da cidade. Logo, densidade - contágio não é uma relação óbvia e mecânica. Deve-se levar em consideração o tipo de densidade, o tipo de relações entre os habitantes dessas áreas densas e como os outros fatores estão participando do processo. Outra demonstração de que nenhum fator dos cinco mencionados conta sozinho vem de outro exemplo do Brasil (que observo, considerando um dos fatores citados por Lussault) no qual as políticas de Estado foram marcadas por uma enorme inoperância e descoordenação e por um negacionismo conspiratório e delirante do governo central. Mesmo assim, até dezembro de 2020 o Brasil estava longe de ter um número de mortes por 100 mil habitantes tão elevado como a Grã-Bretanha, a Itália, os Estados Unidos e a França, por exemplo, ${ }^{6}$ países

6 É certo, que em maio de 2021 esse quadro tinha mudado e o nú mero de mortos por 100 mil habitantes no Brasil ultrapassou todos os exemplos citados, mas isso depois de quase um ano de disparates governamentais. nos quais as políticas estatais foram bem ativas e as populações parecem ter reagido melhor diante das privações do confinamento social.

Na primeira temporada das Chroniques de géo' virale (que terminou no final de abril de 2020) não havia no horizonte a solução da vacina e Lussault argumentava, à época, sobre a impossibilidade de se eliminar o vírus só pelo distanciamento social, não somente pela insustentabilidade econômica e social dessa medida num tempo longo, mas como estratégia epidemiológica única. Então, deveríamos nos acostumar com o vírus na nossa vizinhança interferindo em nossas espacialidades. Parte das reflexões que ele faz nessa direção poderiam perder o sentido diante da imunização geral que, pensamos, a vacinação trará. Porém, considerando o que sabemos por enquanto, os surtos anuais, se sazonais como os da gripe (vírus influenza), podem ter sempre um grau de letalidade importante. Daí as indagações de Lussault: como manter tudo que nos ativa, nos motiva, nos faz humanos com esse vírus em nossas vidas? Qual será agora a boa distância em relação aos outros que vamos imprimir? Esse ensaio sobre o que seria a vida com o vírus também questiona se teremos que alterar nos nossos laços coletivos. Eles teriam que ser fortalecidos? Seremos mais solidários ou mais solitários?

$\mathrm{Na}$ abertura da segunda temporada das Chroniques de géo' virale (março de 2021), um ano após o início da pandemia, a vacinação é uma realidade, mas a imunização ainda não se efetivou e várias medidas não-medicamentosas continuam a ser implementadas no combate à pandemia. E no caso, Lussault faz uma crítica que fecha o raciocínio que descrevemos ao destacar alguns pontos que permeiam as crônicas. Ora, o processo de contágio não corresponde a padrões comuns e nem óbvios. As desigualdades na própria dinâmica planetária da pandemia são difíceis de explicar. O exemplo do continente africano, poupado pelo contágio, ou então a concentração da pandemia na Europa e nas Américas bastam para demonstrar a ausência de padrões, mesmo na escala continental. Se não há padrões, se há dinâmicas distintas, qual o sentido de uma política epidemiológica do tipo zero Covid19, que é um padrão empregado em situações muito diversas. Trata-se de uma estratégia baseada 
Chroniques de géo' virale de Michel Lussault. A epidemia da Covid-19 e o olhar do geógrafo Michel Lussault

em modelizações matemáticas abstratas que supõe uma série de barreiras sanitárias padronizadas como o confinamento restrito, o fechamento de fronteiras, severas quarentenas para viajantes etc., mesmo diante de poucos casos. ${ }^{7}$ Para Lussault, essas medidas antissociais alimentadas por um dado "cientificismo"8 são antidemocráticas, pois esse não deveria ser o papel da ciência. Sua função seria informar precisamente para que as populações também decidissem sobre as medidas a serem tomadas. Além disso, essa estratégia subestima que a pandemia é global e que não é possível chegar ao zero Covid-19 com base na "zero circulação". Subestima a diversidade dos espaços de contágio, que são diversos e não "pequenas ilhas" como os locais a estratégia zero Covid-19 foi modelizada. ${ }^{9}$

Por último, é preciso mencionar que as Chroniques de géo' virale de Michel Lussault não se restringem a reflexões sobre o vírus como operador espacial e a dinâmica da pandemia. Ele também está preocupado com os efeitos psicossociais provocados pelo confinamento e, nesse caso, se espanta com os efeitos da pandemia na ampliação das desigualdades entre homens e mulheres, mesmo nos países em que a emancipação feminina é mais avançada, como na Alemanha (por isso dedica três dos episódios da nova temporada). De fato, é espantoso o que ele demonstra tendo como base pesquisas recentes. 0 cenário é de regressão.

Chroniques de géo' virale revela um "gênero discursivo" próprio que combina uma exposição elaborada por um geógrafo de grande competência intelectual e o meio digital. Nesse caso, fica a impressão de que é possível integrar a esse meio reflexões teóricas, sem concessões, mantendo uma potência comunicativa interessante. Não parece ser um produto acadêmico menor.

\section{Bibliografía}

"Levy, J. (Dir.) (2003). Dictionnaire de la géographie et de l'espace des sociétés. Paris: Belin.

» Lussault, M. (2017). Hyper-lieux. Les nouvelles géographies de la mondialisation. Paris: Le Seuil.

» Lussault, M. (2014). L'Avènement du Monde. Essai sur l'habitation humaine de la Terre. Paris: Le Seuil.

» Lussault, M. (2009). De la lutte des classes à la lutte des places. Paris: Grasset.

» Lussault, M. (2007). L'Homme spatial. La construction sociale de l'espace humain. Paris: Le Seuil.

Jaime Oliva / jtoliva@usp.br

Geógrafo, professor e pesquisador do Instituto de Estudos Brasileiros da Universidade de São Paulo. É autor dos livros Espaço e Comunicativo e Fratura Social em colaboração com Luciana Salazar Salgado, Editora Fino Traço; Cartografia em colaboração com Fernanda Padovesi Fonseca, Editora Melhoramentos. É atualmente vice-presidente da Comissão de Pós Graduação do IEB-USP e responsável pelo projeto coletivo Como Pensar o Brasil Hoje? e também curador do fundo pessoal do geógrafo Milton Santos que está sob a guarda do IEB-USP.
7 Durante a disputa do Australian Open (competição de tênis), em janeiro de 2021, pudemos assistir uma série de restrições sendo impostas pelo governo da área de Melbourne, uma grande metrópole australiana, proibindo o público nos estádios durante à competição e um lockdown severo de alguns dias na cidade porque seis pessoas testaram positivo naquela área.

80 cientificismo epistemológico se caracteriza por um único modelo de cientificidade originário nas ciências da natureza e exatas. Claramente, a proeminência desse modelo deprecia outras possibilidades científicas praticadas pelas ciências sociais.

9 Taiwan e Singapura, por exemplo. 